\title{
A Survey on Information Flow Tools in Alberta's Construction Industry
}

\author{
Mohammad Abdelghani ${ }^{1}$, John Doucette ${ }^{1}$, and Rafiq Ahmad ${ }^{1 *}$ \\ ${ }^{1}$ Department of Mechanical Engineering, University of Alberta \\ *Corresponding author: rafiq.ahmad@ualberta.ca
}

\begin{abstract}
Construction is a major industry in Alberta due to its significant contribution to GDP and employment. Poor communication and inadequate information flow can lead to poor performance on construction projects, in terms of cost, schedule, and quality. Construction 4.0 promotes the implementation of modern information technologies to encourage the digitization of the construction industry and its supply chain. Efficient information flow in the construction supply chain is key for enabling Construction 4.0 and improving the performance of construction projects. This study presents the results of a survey on tools currently used in Alberta's construction industry to exchange information. Results show that Alberta's construction industry mainly depends on emails, meetings, and phone calls to exchange information among stakeholders. These tools are shown to be inefficient means of communication because of delays they arise in providing information, and because of their limitations in storing and disseminating information, which hinders knowledge creation and innovation.
\end{abstract}

\section{KEYWORDS}

Construction; Information; Knowledge; Construction 4.0

\section{INTRODUCTION}

Construction is one of the major industries in Alberta. The value of construction in the province in 2016 is approximately \$27.4 billion according to Government of Alberta data (Government of Alberta, 2018a). In 2017, construction contributed to 10.5\% of Alberta's total employment i.e. 241,000 employed in the industry (Government of Alberta, 2018b). Regardless of the construction contribution to the economy, its supply chain is the least integrated among all other major sectors (Cheng et al., 2010)(Vilasini, 2010). The main reason for the fragmentation of the construction supply chain is the large number of companies and the wide variety of trades that are involved in projects (Nai-Hsin et al., 2010)(London and Vrijhoef, 2002), and the industry's continued reliance on assembling teams on a project-by-project basis with contractors often managing the supply chain (Behera et al., 2015).

This approach has been shown to be inefficient and often leads to miscommunication (Liu et al., 2016). Miscommunication and inadequate information flow can lead to poor performance on construction projects in terms of cost, schedule and quality (Tipili et al., 2014)(Priyadharshini and Satheesh, 2015) (Phong, 2018). Moreover, information flow in a timely, reliable, and uniform manners is one of the main aspects of Construction 4.0 (Wollschlaeger et al., 2017). The concept is adopted from Industry 4.0, the fourth industrial revolution which entails the merging of physical and virtual systems (Osunsanmi et al., 2018). Key Industry 4.0 features within the 
construction value chain are vertical and horizontal, with end-to-end integration of the value networks (Oesterreich and Teuteberg, 2016). Construction 4.0 promotes the implementation of modern technology to encourage the digitization of the construction industry as well as its supply chain (Osunsanmi et al., 2018). Therefore, efficient information flow is a key enabler of good performance on construction projects and supports the development of Construction 4.0. The present paper focuses on understanding the status of Alberta's construction industry in terms of tools currently used to exchange information, and techniques being utilized to improve its efficiency.

\section{METHODS}

The data obtained herein was collected via a cross-sectional survey in the fork of a questionnaire developed using Google Forms and distributed through the Edmonton Construction Association (ECA) e-newsletter. A survey was chosen as the preferred approach because the study is seeking to describe a reality (Mathers et al., 2007). The questionnaire aims to determine the existing tools used by individuals and enterprises to exchange information in Alberta's construction industry. ECA is the largest non-profit construction association in western Canada, and serves all construction sectors, i.e., residential, commercial, institutional, and industrial. The association membership is made up of over 1,300 Edmonton-area firms, including trade contractors, manufacturers, general contractors, suppliers, owners, architects, engineers, and associated members (Edmonton Construction Association, 2018). The survey is divided into five sections. In the first section, participants were asked about their roles and experiences in the industry to understand their professional background. The second section focused on the tools are currently used to exchange information in construction projects. In the third section, questions were asked about tools and methods used to exchange information during specific phases of the project, e.g., procurement, tendering, etc., where multiple partners are involved. In the fourth section, participants were asked about key performance indicators (KPI), including information management KPIs. The last section focused on determining if any tools or techniques are currently being used to improve efficiency.

The survey was sent twice through the ECA e-newsletter; 16 complete responses were received. Using the 1300 members as the survey sample size, 16 responses provide a $95 \%$ confidence level with confidence interval of $24.36 \%$. The results provide an indication for the current practices in the industry regarding the tools currently used to exchange information, but a larger sample size will be required for a higher confidence level. The responses received represented project owners, contractors, subcontractors and consultants who work in all four construction sectors, i.e., residential, industrial, commercial and infrastructure. Most of the participants have more than 5 years of experience as shown in figure 1. 

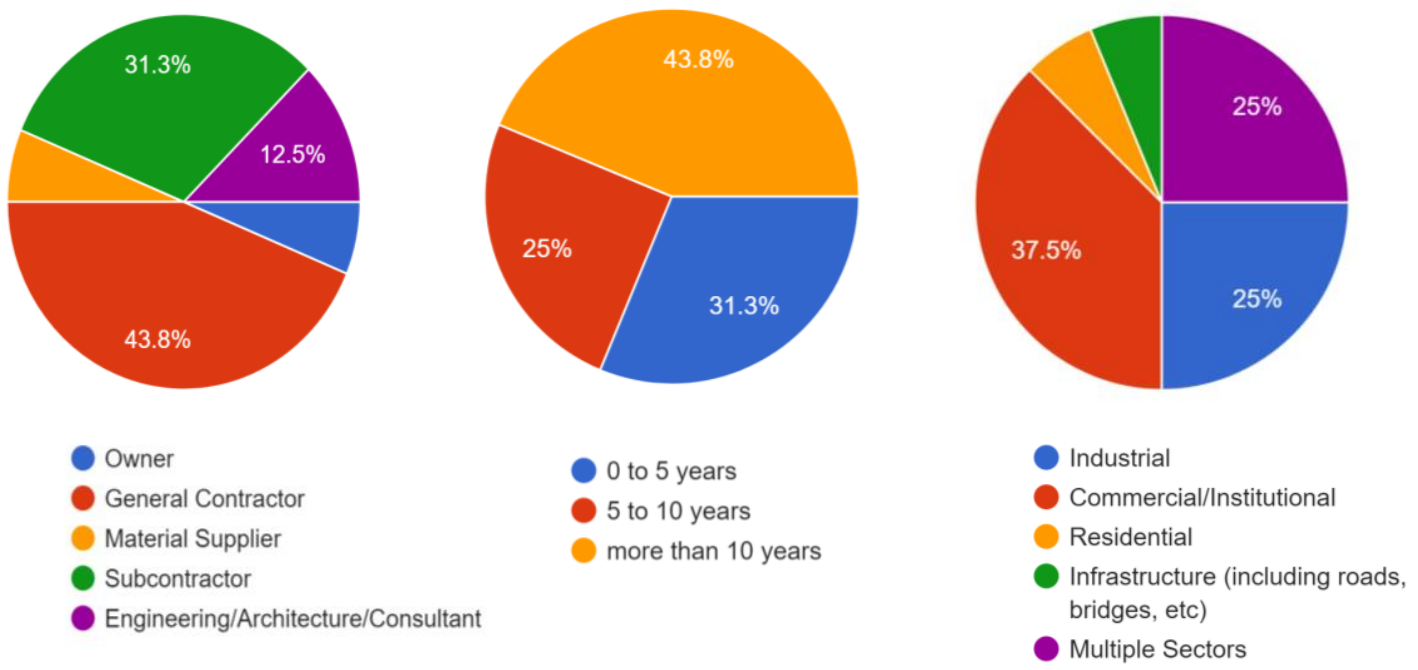

Figure 1. Survey Participants

\section{RESULTS \& DISCUSSION}

There were several tools and methods of communication stated by the participants; these included meetings, phone calls, face to face discussions, emails, correspondence via hard copy, and information management systems (IMS). The respondents were requested to select the frequency for each tool's usage on a scale of 0 through 4 , as follows: never (0), seldom (1), sometimes (2), often (3) and always (4). The frequency index for usage $\left(\mathrm{I}_{\mathrm{F}}\right)$, frequency index for sharing and storing information ( $\mathrm{I}_{\mathrm{S}}$ ), and importance index $\left(\mathrm{I}_{\mathrm{I}}\right)$ are calculated using equations (1)-(3), respectively (Marzouk and El-Rasas, 2014). $\mathrm{I}_{\mathrm{F}}$ is used to rank the information flow tools based on frequency of usage as identified by the participants while Is used to rank the socialization of information for each tool based on the frequency of storing and sharing information as identified by the participants as shown in equations (1) \&(2) respectively (Assaf and Al-Hejji, 2006). The importance index is calculated as a function of $\mathrm{I}_{\mathrm{F}} \& \mathrm{I}_{\mathrm{S}}$ as shown in equation (3).

$$
\begin{aligned}
& \mathrm{IF}_{\mathrm{F}}=\frac{100}{4 \mathrm{~N}} \sum_{i=0}^{i=4} \mathrm{n}_{\mathrm{Fi}} \mathrm{x} \mathrm{d}_{\mathrm{Fi}} \\
& \mathrm{IS}=\frac{100}{4 \mathrm{~N}} \sum_{i=0}^{i=4} \mathrm{nSi}_{\mathrm{X}} \mathrm{dSi}_{\mathrm{S}} \\
& \mathrm{I}_{\mathrm{I}}=\mathrm{I}_{\mathrm{F}} \mathrm{X} \mathrm{I}_{\mathrm{S}} / 100
\end{aligned}
$$

Where,

$\mathrm{n}_{\mathrm{Fi}}=$ Number of respondents who indicated that they used the communication approach in question at a degree of $i$. (e.g. if 10 respondents said they use email "sometimes", then $n_{F 2}=11$ for email).

$\mathrm{d}_{\mathrm{Fi}}=$ Degree of use indicated by the respondent for communication approach in question (e.g. if the respondents mentioned they use email "sometimes", then $\mathrm{d}_{\mathrm{F} 2}=2$ ) 
$\mathrm{n}_{\mathrm{Si}}=$ is the number of respondents who indicated they share, and store information communicated using communication approach in question at a degree of $\mathrm{i}$ (e.g. if 6 respondents said they "always" share and store information communicated by email then $n_{\mathrm{S} 1}=6$ ). $\mathrm{d}_{\mathrm{Si}}=$ Degree of sharing and storing information indicated by the respondents for communication approach in question (e.g. if the respondents mentioned they "sometimes" share and store information communicated by phone then $\mathrm{d}_{\mathrm{S} 2}=2$ ).

$\mathrm{N}=$ is the total number of respondents.

The number of respondents who indicated they use the email "always", "often", "sometimes", "always", "seldom", and "never" are 10, 6, 0, 0 and 0 respectively. Following is a sample Calculation for email $I_{F}$.

$$
\mathrm{I}_{\mathrm{F}}=\frac{100}{4 \times 16}(10 \times 4+6 \times 3+0 \times 2+0 \times 1+0 \times 0)=90.6 \%
$$

The number of respondents who indicated they store and share the information communicated by email "always", "often", "sometimes", "always", "seldom”, and "never" are 5, 6, 4, 0 and 1 respectively. Following is a sample Calculation for email $\mathrm{I}_{\mathrm{I}}$.

$$
\text { Is }=\frac{100}{4 \times 16}(5 \times 4+6 \times 3+4 \times 2+0 \times 1+1 \times 0)=71.8 \%
$$

Using IF \& Is from equations (4) \& (5), II for email is calculated as following:

$$
\mathrm{I}_{\mathrm{I}}=\frac{90.6 \times 71.8}{100}=65.05 \%
$$

IF shows that email is the most used method for communication, followed by meetings, phone calls, correspondence, and IMS, respectively. The participants were also asked about the efficiency of emails in communication, with over $70 \%$ of the responses indicating that they experience late replies for requested information via emails, which causes delays in making decisions. Only $12 \%$ indicated that email is an effective mean of communication, encountering no delays.

Table 1. Frequency index for usage $\left(\mathrm{I}_{\mathrm{F}}\right)$

\begin{tabular}{lc}
\hline Communication Method & $\mathrm{I}_{\mathrm{F}}$ \\
& $(\%)$ \\
\hline Emails & 91 \\
Meetings & 80 \\
Phone calls \& face to face discussions & 69 \\
Correspondence (hard Copies) & 56 \\
Information Management System (IMS) & 31 \\
\hline
\end{tabular}

Knowledge is one of the essential assets in construction industry because of its role in innovation and value creation (Javernick-Will and Scott, 2009). Knowledge is divided into tacit and explicit 
knowledge. Explicit knowledge is stored and can be shared in the form of data, figures, etc., where tacit knowledge is deeply routed in individuals' behaviours and has to be learned through interactions (Pathirage et al., 2007). The interaction between tacit and explicit leads to knowledge creation. A four-stage conversion model known as SECI (Socialization, Externalization, Combination, and Internalization) is built to show the steps of converting tacit knowledge to explicit and ultimately knowledge creation (Nonaka et al., 2000). The first step, socialization, is where information is shared at the individual employee level through various means of communication. At the externalization stage, tacit knowledge is transformed into formal knowledge that is stored and shared in formal language such as figures, charts, manuals, etc. The third stage, combination, is where explicit knowledge is placed into a systematic structure. Finally, the fourth is internalization, where individuals absorb the explicit knowledge and create their own tacit knowledge (Zhang and Chen, 2016). Based on the SECI model, tools and means of communication are crucial for knowledge creation and for transferring tacit knowledge into explicit knowledge. Furthermore, socialization and externalization are highly dependent on the means of communication utilized.

The participants were asked about the frequency of storing and sharing information communicated by emails, meetings, phone calls and face to face discussions. As shown in table 2 , the Is for emails is $72 \%$, while it is $55 \%$ for meetings and $19 \%$ for phone calls. Considering that emails, meetings, phone calls, and face to face discussions are the most common means of communication used in the Alberta construction industry, with minimal use of IMS, we can conclude that a sizeable amount of exchanged information not adequately socialized or externalized and remains at the individual employee level. This hinders the knowledge creation which adversely impacts innovation and value creation.

Table 2. Frequency index for sharing and storing information ( $\left.\mathrm{I}_{\mathrm{S}}\right)$

\begin{tabular}{lc}
\hline Communication Method & $\mathrm{I}_{\mathrm{S}}$ \\
& $(\%)$ \\
\hline Emails & 72 \\
Meetings & 55 \\
Phone calls \& face to face discussions & 19 \\
Correspondence (hard Copies) & N/A \\
Information Management System (IMS) & N/A \\
\hline
\end{tabular}

The importance index for each tool was calculated based on the frequency of usage as well as the information storage and sharing frequency index, with results shown in table 3 . Emails have an importance index of $65 \%$ while phone calls and face-to-face discussions scored the lowest at $13 \%$. Taking into consideration the usage, storage, and sharing frequency factors, the current tools for information flow in Alberta's construction industry is not as effective as it could be and doesn't support knowledge creation based on SECI model. The study results are in accordance with similar studies completed in other regions where construction industry faces similar 
challenges in terms of inefficient communication and loss of information (Sarshar and Isijdag, 2006)(Barakat, 2009) (Khan et al., 2015)(Qady et al., 2013).

Table 3. Importance index $\left(\mathrm{I}_{\mathrm{I}}\right)$

\begin{tabular}{lc}
\hline Communication Method & $\mathrm{I}_{\mathrm{I}}$ \\
& $(\%)$ \\
\hline Emails & 65 \\
Meetings & 44 \\
Phone calls \& face to face discussions & 13 \\
Correspondence (hard Copies) & N/A \\
Information Management System (IMS) & N/A \\
\hline
\end{tabular}

Finally, participants were asked about key performance indicators (KPIs) and how they measure the performance of their information management systems. $69 \%$ of respondents stated that they don't measure the performance of their IMS at all. Furthermore, participants were asked if they use lean management tools such as value-stream mapping to identify and eliminate waste within their processes and systems. Value-stream mapping came to prominence in the latter half of the 20th century, forming part of the foundation of the Toyota Production System, and has become one of the integral aspects of lean management philosophy (Rohac and Januska, 2015)(Liker, 2004). VSM is a graphic representation of value flowing from the receiving customer's order all the way to the delivery of final product. It divides activities into value adding and non-value adding activities (Rohac and Januska, 2015). Most importantly from our perspective, VSM is an effective tool for identifying "waiting" wastes in information flow systems. Approx. 93.8\% of the participants mentioned that they are not familiar or haven't used value-stream mapping in their jobs. The survey results support our assertation that the construction industry in Alberta hasn't yet adopted VSM (and other lean management techniques).

\section{CONCLUSION}

This study aims to determine the existing tools used to exchange information in Alberta's construction industry and evaluate the effectiveness of these tools. A survey was conducted to collect data from industry participants. It was found that Alberta's construction industry mainly relies on emails, meetings, phone calls, and face to face discussions as a means of communication. Email has the highest frequency use index of $91 \%$, followed by meetings, phone calls, correspondence, and IMS, at $80 \%, 69 \%, 56 \%$, and 31\%, respectively. We also find that most of the information within an organization stays at the individual employee level and is unlikely to be stored or shared formally with others. This hinders the transfer of construction knowledge from tacit to explicit knowledge, which impacts knowledge capitalization, innovation, and value creation. The construction industry in Alberta hasn't widely adopted VSM 
or other lean management techniques. More accurate results with a better confidence level and confidence intervals can be achieved by higher participation rates in the survey, with low response rate (16 out of approximately 1300) being the primary limitation for the present study.

\section{ACKNOWLEDGEMENTS}

The authors would like to thank and acknowledge the Edmonton Construction Association for their support and assistance in distributing the survey.

\section{REFERENCES AND CITATIONS}

Assaf, S.A., and Al-Hejji, S. (2006). Causes of delay in large construction projects: International Journal of Project Management, Vol. 24, No. 4, pp. 349-357.

Barakat, T.A.H.T. (2009). A hybrid model of communication and information management in mega construction projects in Dubai using a new critical success factor approach. $\mathrm{PhD}$ Thesis, University of Loughborough.

Behera, P., Mohanty, R.P., and Prakash, A. (2015). Production Planning \& Control Understanding Construction Supply Chain Management Understanding Construction Supply Chain Management: Production Planning \& Control, Vol. 26, No. 16, pp. 13321350 .

Cheng, J.C.P., Law, K.H., Bjornsson, H., Jones, A., and Sriram, R. (2010). A service oriented framework for construction supply chain integration: Automation in Construction, Vol. 19, No. 2, pp. 245-260.

Edmonton Construction Association, 2018 . <https//www.edmca.com/> ( Dec. 27, 2018)

Government of Alberta (2018a). "Gross Domestic Product." <https://economicdashboard. alberta.ca /GrossDomesticProduct\#type> (Dec. 22, 2018).

Government of Alberta (2018b). Industry Profiles 2018 Construction Industry. ISBN 978-14601-3774-1 ISSN 2292-8898 < https://work.alberta.ca/documents/industry-profileconstruction.pdf $>$ ( Dec. 19, 2018).

Javernick-Will, A.N., and Scott, W.R. (2009). Who Needs to Know What? Institutional Knowledge and International Projects: Journal of Construction Engineering and Management, Vol. 136, No. 5, pp. 546-557.

Khan, K.I.A., Flanagan, R., and Lu, S.-L. (2015). Managing the complexity of information flow for construction small and medium-sized enterprises (CSMEs) using system dynamics and collaborative technologies: Proceedings 31 st Annual ARCOM Conference, 7-9 September 2015, pp. 1177-1186.

Liker, J. (2004). The Toyota Way: 14 management principles from the worlds greatest manufacturer, McGraw-Hill, New York.xxii,330s.

Liu, R., Chua, V.C., and Com, V. (2016). THEORETICAL DIGITALIZATION OF INFORMATION FLOW IN THE CONSTRUCTION SUPPLY CHAIN: International Journal of Management Research and Business Strategy, Vol. 5, No. 1. pp.10-27

London, K., and Vrijhoef, R. (2002). Construction Supply Chain Modeling : a Research Review and Interdisciplinary Research Agenda: Management, Vol. 3, No. 3, pp. 129-148.

MARTIN WOLLSCHLAEGER, THILO SAUTER, A.J.J. (2017). The future of industrial communication: Industrial and Engineering Chemistry, Vol. 12, No. 4, pp. 370-376.

Marzouk, M.M., and El-Rasas, T.I. (2014). Analyzing delay causes in egyptian construction 
projects: Journal of Advanced Research, Vol. 5, No. 1, pp. 49-55.

Mathers N, Fox N. and Hunn A. Surveys and Questionnaires. The NIHR RDS for the East Midlands / Yorkshire \& the Humber, 2007. pp. 2-3.

Nai-Hsin, P., Yung-Yu, L., and Nang-Fei, P. (2010). Enhancing construction project supply chains and performance evaluation methods: a case study of a bridge construction project: Canadian Journal of Civil Engineering, Vol. 37, No. 8, pp. 1094-1106.

Nonaka, I., Toyama, R., and Konno, N. (2000). SECI, Ba and Leadership: A Unified Model of Dynamic Knowledge Creation: Long Range Planning, Vol. 33, No. 1, pp. 5-34.

Oesterreich, T.D., and Teuteberg, F. (2016). Understanding the implications of digitisation and automation in the context of Industry 4.0: A triangulation approach and elements of a research agenda for the construction industry: Computers in Industry, Vol. 83, pp. 121139.

Osunsanmi, T.O., Aigbavboa, C., and Oke, A. (2018). Construction 4 . 0 : The Future of South Africa Construction Industry: International Scholarly and Scientific Research \& Innovation, Vol. 12, No. 3, pp. 2017-2018.

Pathirage, C.P., Amaratunga, D.G., and Haigh, R.P. (2007). Tacit knowledge and organisational performance: Construction industry perspective: Journal of Knowledge Management, Vol. 11, No. 1, pp. 115-126.

Phong, N. (2018). Application of Supply Chain Management in Construction Industry: Advances in Science and Technology Research Journal, Vol. 12, No. 2, pp. 11-19.

Priyadharshini, N.S., and Satheesh, K.S. (2015). Project Communication : Is Key To Productive Construction and It' S Research Needs in the Future of Construction Engineering and Management: International Journal of Science, Technology \& Management, Vol. 4, No. 01, pp. 1493-1499.

Qady, M. Al, Kandil, A., and Asce, M. (2013). Document Management in Construction : Practices and Opinions: Vol. 139, No. 10, pp. 1-7.

Rohac, T., and Januska, M. (2015). Value stream mapping demonstration on real case study: Procedia Engineering, Vol. 100, pp. 520-529.

Sarshar, M., and Isijdag, U. (2006). "A survey of ICT use in the Turkish construction industry", Engineering, Construction and Architectural Management, Vol. 11 Issue: 4, pp.238-247.

Tipili, L.G., Ojeba, P.O., and Sa 'adiya Ilyasu, M. (2014). Evaluating the effects of communication in construction project delivery in Nigeria: Global Journal of Environmental Science and Technology, Vol. 2, No. 5, pp. 2360-7955.

Vilasini, N., Gamaje, J.R (2010). Implementing Value Stream Mapping Tool in the Construction Industry. International Research Conference on Sustainability in Built Environment (June 2010). pp 256-265.

Zhang, L., and Chen, X. (2016). Role of Lean Tools in Supporting Knowledge Creation and Performance in Lean Construction: Procedia Engineering, Vol. 145, pp. 1267-1274. 